\title{
Multiple aneuploidies in the oocytes of balanced translocation carriers: a preimplantation genetic diagnosis study using first polar body
}

\author{
A. Pujol ${ }^{1}$, M. Durban ${ }^{1}$, J. Benet ${ }^{1}$, I. Boiso ${ }^{2}$, J. M. Calafell ${ }^{3}$, \\ J. Egozcue ${ }^{1}$ and J. Navarro ${ }^{1}$ \\ ${ }^{1}$ Departament de Biologia Celular, Fisiologia i Immunologia, Unitat de Biologia, Facultat de Medicina, \\ Universitat Autònoma de Barcelona, E-08193 Bellaterra, Spain; ${ }^{2}$ Servei de Medicina de la Reproducció, \\ Institut Universitari Dexeus, Pg. Bonanova 89-91, E-08017 Barcelona, Spain; and ${ }^{3}$ Institut Clínic de \\ Ginecologia, Obstetrícia i Neonatologia, Hospital Clínic - Institut d'Investigacions Biomèdiques Agustí \\ Pi i Sunyer, Villarroel 170, E-08036 Barcelona, Spain
}

Preimplantation genetic diagnosis (PGD) of first polar bodies (1PBs) has been used in carriers of balanced chromosomal reorganizations and also for aneuploidy screening. Although an acceptable number of normal or balanced embryos is usually obtained using PGD in translocation carriers, the pregnancy rate is disappointingly low. To determine whether aneuploidy of chromosomes not involved in the chromosome rearrangements could be the cause of the low pregnancy rates achieved, the present authors analysed the segregation products of three translocation carriers, $t(8 ; 13)(q 24.1 ; q 22)$ and two Robertsonian (Rob) $(13 ; 14)$, using $1 \mathrm{PBs}$, and afterwards another eight chromosomes in the same 1PBs, for a total of 10 chromosomes in each $1 \mathrm{~PB}$, that is chromosomes $1,8,13,14,15,16,17,18,21$, 22 and $X$. In the reciprocal translocation, chromosomes with different chromatids due to meiotic recombination were found. Only one out of nine 1PBs was normal for the reorganization products but no aneuploidies were found after PGD in this case. In the two balanced Rob(13;14), six out of 12 and four out of 11 PBs were normal or balanced for the reorganization but only one oocyte was euploid for all the chromosomes analysed in each case; a single embryo transfer was made in both but no pregnancy was achieved. The incidence of aneuploidy for the chromosomes not involved in the Robertsonian translocations was extremely high $(91.7 \%$ and $81.8 \%)$. Extra chromosomes were present in most of the aneuploid oocytes $(81.8 \%$ and $90 \%)$. The reason for this increase could be the tendency to nondisjunction related to advanced maternal age combined with an interchromosomal effect resulting in the presence of synaptic errors in other chromosome pairs.

\section{Introduction}

Preimplantation genetic diagnosis (PGD) is widely used (ESHRE PGD Consortium Steering Committee, 2002), predominantly for detecting chromosome abnormalities, analysing one or two blastomeres by fluorescent in situ hybridization (FISH) (Munné et al., 1998a; Conn et al., 1999; Van Assche et al., 1999; Verlinsky, 1999; Durban et al., 2001; Magli et al., 2001) or single gene defects using PCR (Handyside et al., 1990; Harper et al., 2002). Although the incidence of mosaicism detected in embryos for the chromosomes involved in a translocation can be as high as $73 \%$ (Iwarsson et al., 2000; Emiliani et al., 2003), PGD analysis of blastomeres is extensively used. PGD analysis of the first polar body (1PB) can be used to avoid post-zygotic mosaicism in cases in which

Email: aida@pujolmuntala.es the chromosome abnormality or the single gene defect has a maternal origin (Verlinsky et al., 1996; Munné et al., 1998b, 2000a; Durban et al., 2001). The reasons for performing a PGD analysis in 1 PB are seldom ethical (to avoid discarding embryos); more often, the reasons are technical. As the 1PB is in metaphase II (MII), good chromosome morphology extensions (Durban et al., 1998) can be obtained and all types of hybridization probes, including whole chromosome painting (WCP), can be applied. Several rounds of FISH can be applied as biopsies of $1 \mathrm{PBs}$ can be performed immediately after follicular puncture. Durban et al. (2001) reviewed the results of PGD using $1 \mathrm{PBs}$ in female carriers of balanced Robertsonian and reciprocal translocations. In this study, the use of intracytoplasmic sperm injection (ICSI) before the 1PB biopsy produced fertilization rates comparable to those obtained in cycles without PGD. The protocol recommended by Durban et al. (2001) 
Table 1a. General patient data, details of fluorescent in situ hybridization (FISH) and results of IVF in the reciprocal translocation carrier

\begin{tabular}{|c|c|c|}
\hline Patient and karyotype & Patient 1: 45,XX, der(8;13)(q24.1;q22) & \\
\hline Age & 34 & \\
\hline $\mathrm{COC}$ & 12 & \\
\hline MII oocytes & 11 & \\
\hline Biopsied oocytes & 11 of $11(100 \%)$ & \\
\hline Fixed 1PBs & 10 of $11(90.9 \%)$ & \\
\hline $\mathrm{FISH}$ & Probes & FISH efficiency \\
\hline First round & LSI 13, WCP 8 & 10 of $10(100 \%)$ \\
\hline Second round & WCP 13, Tel 8 & 9 of $10(90 \%)$ \\
\hline Third round & LSI13, CEP16, CEP18, LSI21, LSI22 & 6 of $9(66.7 \%)$ \\
\hline Fourth round & CEPX, CEP1, CEP15, CEP17 & 8 of $8(100 \%)$ \\
\hline \multicolumn{3}{|l|}{ Fertilization } \\
\hline $1 \mathrm{PN}$ & - & \\
\hline $2 \mathrm{PN}$ & 6 of $11(54.6 \%)$ & \\
\hline $3 \mathrm{PN}$ & 4 of $11(36.4 \%)$ & \\
\hline Degenerated & 1 of $11(9 \%)$ & \\
\hline Embryo morphology & 2 embryos with $\geqslant 4$ cells on day 2 & \\
\hline Embryos transferred & - & \\
\hline$\beta$ hCG & - & \\
\hline
\end{tabular}

COC: cumulus-oocyte complex; MII: metaphase II; 1PB: first polar body; PN: pronucleus.

also permits a blastomere analysis in those embryos in which a diagnosis of the $1 \mathrm{~PB}$ is not achieved or shows an abnormality that could be rescued in the second meiotic division. ICSI is always performed with PGD$1 \mathrm{~PB}$ to synchronize the evolution of embryos and to avoid a possible polypenetration through the opening in the zona pellucida when the 1PB undergoes biopsy before insemination. The use of the $1 \mathrm{~PB}$ allows the differentiation between balanced and normal karyotypes and this is one of the reasons it is recommended for the analysis of translocations (Coonen et al., 2000).

Although PGD has been considered a useful tool for translocation carriers and allows an improvement in their pregnancy rates (ESHRE PGD Consortium Steering Committee, 2002), it is not unusual to obtain two or three normal or balanced embryos with good morphology for transfer, and still not achieve a pregnancy. This difficulty might be due to several factors, one of which could be the presence of aneuploidies affecting chromosomes other than those involved in the translocation. By analysing embryos by PGD in Robertsonian translocation carriers, Gianaroli et al. (2002) found 31\% aneuploidy in translocation non-related chromosomes, whereas only $6 \%$ aneuploidy was found in reciprocal translocation carriers. Gianaroli et al. (2002) suggested that an interchromosomal effect could play a role in Robertsonian translocation carriers.

In the present study, the analysis of the chromosomes implicated in two Robertsonian and one reciprocal translocation was complemented using PGD analysis of $1 \mathrm{PBs}$, with the analysis of the chromosomes involved in the most common autosomal chromosome abnormalities
(Egozcue, 1996; Verlinsky et al., 1999; Munné et al., 2000b) and of chromosomes $X, 1,15$ and 17 which could also contribute to the low pregnancy rates achieved, as suggested by Bahçe et al. (1999).

\section{Materials and Methods}

Three patients were studied (Table $1 \mathrm{a}, \mathrm{b}$ ); all patients gave their informed consent. The project was approved by the local ethics committee. The three clinical cases were performed in collaboration with two different reproductive centres. For this reason, the biopsy methods were different. Patient 1 was a 34-year-old female carrier of a balanced reciprocal translocation $\mathrm{t}(8 ; 13)(\mathrm{q} 24.1 ; \mathrm{q} 22)$. The semen sample of the husband of patient 1 was normal. The carrier status was detected in a routine karyotype study for sterility. The wife of the brother of patient 1 had had a spontaneous abortion, but the karyotype of these relatives was unknown.

Patient 2 was a 39-year-old female carrier of a balanced Robertsonian translocation $\mathrm{t}(13 ; 14)$. The semen sample of the husband of patient 2 showed a moderate asthenozoospermia. The couple had five first trimester miscarriages during the last 9 years; three were spontaneous and the other two were therapeutic abortions after abnormal results in the ultrasound scanning controls. In only one of these miscarriages, chorion villi samples were obtained and analysed showing a trisomy 13 , with a 46 , $\mathrm{XY},-14$, + Rob(13;14) karyotype. The last spontaneous abortion was after PGD using 1PBs for the analysis of chromosomes 13 and 14 . In that cycle (patient P 
Table 1b. General patient data, details of fluorescent in situ hybridization (FISH) and results of IVF in the Robertsonian (13;14) carriers

\begin{tabular}{|c|c|c|c|c|}
\hline Patient and karyotype & Patient 2: 45,XX, der(13;14)(q10;q10) & & Patient 3: 45,XX, der(13;14)(q10;q10) & \\
\hline Age & 39 & & 36 & \\
\hline $\mathrm{COC}$ & 13 & & 23 & \\
\hline MII oocytes & 13 & & 12 & \\
\hline Biopsied oocytes & 13 of $13(100 \%)$ & & 12 of $12(100 \%)$ & \\
\hline Fixed 1PBs & 13 of $13(100 \%)$ & & 12 of $12(100 \%)$ & \\
\hline $\mathrm{FISH}$ & Probes & FISH efficiency & Probes & FISH efficiency \\
\hline First round & LSI 13, Tel 14 & 12 of $13(92.3 \%)$ & LSI13, CEP16, CEP18, LSI21, LSI22 & 11 of $11(100 \%)$ \\
\hline Second round & LSI13, CEP16, CEP18, LSI21, LSI22 & 12 of $12(100 \%)$ & WCP 13, Tel 14 & 10 of $11(91 \%)$ \\
\hline Third round & CEPX, CEP1, CEP15, CEP17 & 11 of $12(91.6 \%)$ & CEPX, CEP15, CEP17 & 7 of $11(63.6 \%)$ \\
\hline Fourth round & WCP14 & 3 of $3(100 \%)$ & - & - \\
\hline \multicolumn{5}{|l|}{ Fertilization } \\
\hline 1PN & 1 of $13(7.7 \%)$ & & - & \\
\hline $2 \mathrm{PN}$ & 11 of $13(84.6 \%)$ & & 8 of $12(66.7 \%)$ & \\
\hline $3 \mathrm{PN}$ & - & & - & \\
\hline Degenerated & 1 of $13(7.7 \%)$ & & - & \\
\hline Embryo morphology & 5 embryos with $\geqslant 6$ cells on day 3 & & 2 embryos with $\geqslant 6$ cells on day 3 & \\
\hline Embryos transferred & 1 & & 1 & \\
\hline$\beta \mathrm{hCG}$ & Negative & & Negative & \\
\hline
\end{tabular}

COC: cumulus-oocyte complex; MII: metaphase II; 1PB: first polar body; PN: pronucleus.

in Durban et al. (2001)), three embryos, one normal and two balanced, were transferred. A pregnancy with positive heart beat was achieved but the patient aborted at 7 weeks.

Patient 3 was a 36-year-old female carrier of a balanced Robertsonian translocation $\mathrm{t}(13 ; 14)$. The semen sample of the husband of patient 3 showed a slight oligozoospermia and moderate asthenozoospermia. The couple had five miscarriages which were not cytogenetically analysed and had undergone several PGD cycles analysing chromosomes 13 and 14, four cycles of PGD analysing blastomeres and one PGD cycle using 1PBs. In blastomere PGDs, two embryos were transferred in the second cycle but no pregnancy was achieved; in the fourth cycle, one embryo was transferred but the patient miscarried. In the PGD-1PB, four embryos were normal or balanced for the translocation products; three embryos were transferred; $\beta$-hCG was positive but ultrasound scanning revealed only the presence of an empty sac; the patient miscarried.

The patients underwent gonadotrophin stimulation as performed in the two reproductive centres where they were treated. The dosages were adjusted based on their response to treatment.

At $2 \mathrm{~h}$ or less after oocyte retrieval and using a recommended protocol (Durban et al., 2001), ICSI was performed in fresh metaphase II oocytes and, immediately after, the 1PB was biopsied by a mechanical method (PZD) in patient 1 or using a laser beam $(1.48 \mu \mathrm{m}$ non-contact diode laser; Fertilase, Medical Technologies, Montreux) in patients 2 and 3. Biopsy and fixation were carried out as described by Durban et al. (1998) and Pujol et al. (2003). Fixed 1PBs were also treated as described (Pujol et al., 2003) and three or four rounds of FISH were performed with several fluorescent probe combinations (Table 1).

The chromosomes implicated in the reorganization were analysed in one or two rounds of FISH. In patient 1, LSI 13 (Vysis, NY) labelled with SpectrumGreen and WCP 8 labelled with Cy3 (Cambio, Cambridge) were applied in a first round and WCP 13 (Cambio) labelled with $\mathrm{Cy} 3$ and Tel $8 q$ (Vysis) labelled with SpectrumOrange were used in a second round. In patient 2, a first round using LSI 13 and Tel 14 probes (Vysis) labelled respectively with SpectrumGreen and SpectrumOrange was performed. After the analysis of the chromosomes involved in the reorganization, aneuploidy screening was performed in patients 1 and 2. Chromosomes 13, 16, 18, 21 and 22 labelled, respectively, with SpectrumRed, SpectrumAqua, SpectrumBlue, SpectrumGreen and SpectrumGold (MultiVysionPB, Vysis) were analysed in subsequent rounds. In the last round of FISH, a mixture of X, 1, 15 and 17 centromere probes (CEP) labelled, respectively, with SpectrumAqua, SpectrumOrange, SpectrumGreen and SpectrumOrange/SpectrumGreen (Vysis) was applied. After transfer in patient 2, 1PBs from three aneuploid oocytes (Table 2, cells 7, 10 and 12) were analysed with WCP 14 labelled with SpectrumOrange (Vysis) to complete the diagnosis. In patient 3, chromosomes 13, 16, 18, 21 and 22 (MultiVysionPB, Vysis) were analysed first, WCP 13 and Tel 14 probes (Vysis) were applied second and then a mixture of CEP15, CEP17 and CEPX was used. A blastomere biopsy was performed in five embryos because the 1PB presented a chromatid alteration that could be arranged in the second meiotic division, the diagnosis was not clear or the 1PB had been lost. 

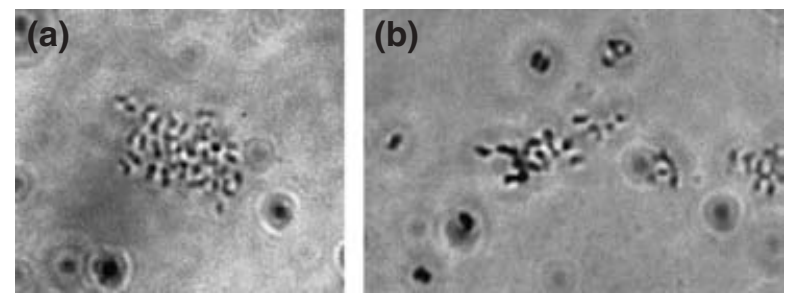

Fig. 1. Phase-contrast images to show chromosome spreading which is not visible in some fluorescent in situ hybridization (FISH) images due to brightness caused by staining with 4,6-diamino-2phenylindole (DAPI). (a) First polar body (1PB) number 3, patient 1 ; (b) 1PB number 5, patient 2.

\section{Results}

Twelve cumulus-oocyte complexes (COCs) were retrieved in patient 1, 11 MII oocytes were obtained; they were all successfully biopsied and ten of the biopsied 1PBs (90.9\%) were correctly fixed. Thirteen COCs were retrieved in patient 2; all of them contained MII oocytes and they were all successfully biopsied and fixed. Twenty-three COCs were retrieved in patient $3 ; 12$ MIl oocytes were obtained and they were all successfully biopsied and fixed (Table 1).

The quality of $1 \mathrm{~PB}$ chromosome preparations obtained was good (Fig. 1), although when 4,6-diamino-2phenylindole (DAPI) was applied, its brightness made the spread look worse. Even when a high-quality spread was not obtained, the chromosome complements were complete and FISH analysis was properly made using multiple rounds of FISH (Table 1).

Cytogenetic data of meiotic segregation and aneuploidy screening analysis are shown in Table 2 and some of the 1PB FISH images obtained in the three clinical cases are shown in Fig. 2.

\section{Segregation of the rearranged chromosomes}

For patient 1, the chromosomes involved in the reciprocal translocation segregated as follows: one 2:2 alternate segregation, three $2: 2$ alternate or adjacent 1 with a recombinant chromosome 13 (with a normal and a derivative chromatid 13), one 2:2 adjacent 2, and four 3:1 segregations.

Only one out of nine 1PBs was normal or balanced $(11.1 \%)$ and two cells had a normal chromosome 8 and a recombinant chromosome 13 that could produce normal or abnormal embryos with a $50 \%$ probability (Fig. $2 \mathrm{~g}$ ). Two 1PBs were lost during fixation or FISH procedures (Table 2). Chromatid pre-division was not observed in any of the analysed $1 \mathrm{PBs}$ for the chromosomes implicated in the reciprocal translocation. Chromatid changes were only observed in the chromosomes involved in the translocation.

For patient 2, the chromosomes involved in the Robertsonian translocation segregated as follows: six 2:1 alternate segregations, two 2:1 adjacent segregations and two 3:0 segregations. There were two cells with alternate or adjacent segregation (chromosome 14 was undiagnosed) and one 1PB was lost during FISH (Table 2). There was a total of six normal or balanced $1 \mathrm{PBs}(50 \%)$. Chromatid pre-division did not affect the chromosomes involved in the translocation, but was observed for other chromosomes during PGD for aneuploidy screening (PGD-AS).

For patient 3, the chromosomes involved in the Robertsonian translocation segregated as follows: four 2:1 alternate segregations, five 2:1 adjacent segregations (two of them with a missing chromatid 14 that could result in normal embryos with a probability of $50 \%$ ) and one 3:0 segregation. There was one $1 \mathrm{~PB}$ with a 2:1 adjacent or 3:0 segregation (undiagnosed for chromosome 14) and one parthenogenetic embryo in which the $1 \mathrm{~PB}$ was lost (Table 2). There was a total of four normal or balanced 1PBs (36.4\%). Chromatid pre-division of the chromosomes involved in the translocation affected $50 \%$ of $1 \mathrm{PBs}$ (five of ten) and was also observed for other chromosomes during PGD-AS.

\section{Aneuploidy screening}

Analysis of the chromosomes not involved in the translocations produced the following results (Table 2 and Fig. 2). For patient 1, only one hyperhaploidy for chromosome 1 (Table 2, cell number 7) was observed. For patients 2 and 3, multiple and random abnormalities were found. For patient 2 there were seven hyperhaploidies and seven hypohaploidies affecting whole chromosomes, and five hyperhaploidies and five hypohaploidies affecting single chromatids. For patient 3 there were three hyperhaploidies and one hypohaploidy affecting whole chromosomes, and four hyperhaploidies and four hypohaploidies affecting single chromatids.

Chromatid pre-division affecting chromosomes not involved in the rearrangement was observed for patients 2 and 3 . The chromosomes more often implicated in aneuploidies for patient 2 were chromosome 16 (five times); 1,18 and 22 (four times); $X$ (three times); 17 (twice) and 15, 21 (once). The chromosomes more often implicated in aneuploidies for patient 3 were chromosome $X$ (three times), chromosomes 16, 17, 21 and 22 (twice) and chromosome 15 (once). No relationship between this frequency and the size of the chromosomes was observed.

From the results obtained for the eight chromosomes analysed by PGD-AS and not implicated in the translocation, it was possible to calculate the risk of abnormal chromosomal segregation and aneuploidy for each chromosome in each patient (Table 3). The abnormal segregation percentage of each chromosome varied between $0 \%$ and $1.92 \%$ (patient 1 ), $0.9 \%$ and $5.40 \%$ (patient 2), and $0 \%$ and $3.64 \%$ (patient 3 ). The average risk of aneuploidy for the eight chromosomes was $0.24 \%, 3.11 \%$ and $2.20 \%$, respectively. 

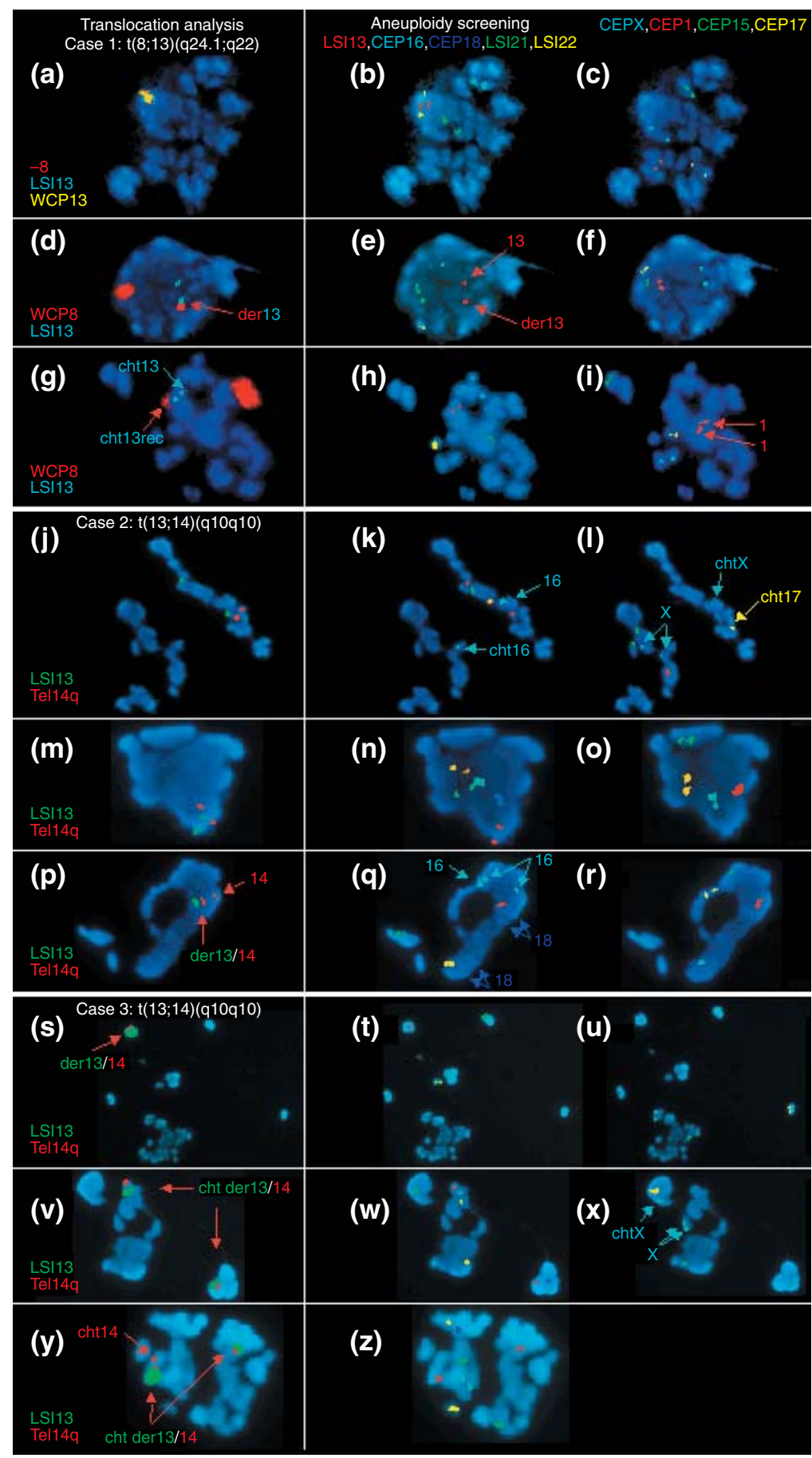

Fig. 2. Fluorescent in situ hybridization (FISH) images of first polar bodies (1PBs). The colours of each probe used are indicated to the left of the 1PB images in (a), (d) and (g) for patient 1 ; in (j), (m) and (p) for patient 2; and in (s), (v) and (y) for patient 3 and on the top of each column for preimplantation genetic diagnosis-aneuploidy screening (PGD-AS). The colours are the same as the probes used to analyse the 1PBs except in (a), (d) and (g), which are yellow for WCP 13, red for WCP 8 and cyan for LSI 13. Abnormalities and derivative chromosomes are indicated by arrows. Patient 1: (a,b,c) 1PB number 1 (a) -8, 13, (b) 13, 16, 18 (close to a chromatid 21), 21, 22, (c) X, 1, 15, 17; (d,e,f) 1PB number 4 (d) 8, 13, der8/13, (e) 13, der8/13 (as shown in d), 16, 18 (separated chromatids, top left and between gold and red signals), 21, 22, (f) X, 1, 15, 17; (g,h,i) 1PB number 7 (g) 8, recombinant chromosome 13 (with one normal and one derivative 8/13 chromatid), (h) 13, 16, 18, 21, 22, (i) X, +1, 15, 17. Patient 2: (j,k,l) 1PB number 4 (j) 13, 14, (k) 13, 16, + chromatid 16, 18, 21, 22, (l) X, + chromatid X, 1, 15, - chromatid 17; (m,n,o) 1PB number 6 , euploid for all the analysed chromosomes, chromosome 18 is between cyan and red signals; (p,q,r) 1PB number 13 (p) 14, der13/14, (q) 13, 16, +16, 18, +18, 21, 22, (r) X, 1, 15, 17. Patient 3: (s,t,u) 1PB number 10 (s) der13/14, (t) euploid for all the analysed chromosomes, chromosome 16 (cyan) is next to chromosome 22 (yellow), (u) euploid for all the analysed chromosomes, CEP 1 was not applied; $(v, w, x) 1$ PB number 2 (v) der13/14 with separated chromatids, (w) euploid for all the analysed chromosomes, $(x)+$ chromatid X, CEP 1 was not applied; $(y, z) 1$ PB number 6 (y) der13/14 with separated chromatids, + chromatid 14, $(\mathrm{z})+$ chromosome $21,+$ chromatid 22. 
Table 2. Patient data and first polar body (1PB) fluorescent in situ hybridization results for the ten chromosomes analysed and diagnosed, segregations observed for each chromosome re-organization, intracytoplasmic sperm injection (ICSI) results and embryos transferred

\begin{tabular}{|c|c|c|c|c|c|c|}
\hline $\begin{array}{l}\text { Patient } 1 \\
\text { Cell number }\end{array}$ & $\begin{array}{l}\text { Fixed } \\
1 \mathrm{~PB} / \mathrm{Blt}\end{array}$ & Euploidy & Aneuploidy & $\begin{array}{l}\text { Undiagnosed } \\
\text { chromosomes }\end{array}$ & $\begin{array}{l}8,13, \text { der } 8 / 13 \\
\text { segregation }\end{array}$ & $\begin{array}{l}\text { ICSI results } \\
\text { and transfer }\end{array}$ \\
\hline 1 & Yes/No & $X, 1,13,15,16,17,18,21,22$ & -8 & - & $3: 1$ & $3 \mathrm{PN}$ \\
\hline 2 & Yes/No & $X, 1,15,16,18,21,22$ & 8,der8,-13 & 17 & $2: 2$ adjacent 2 & Fertilized \\
\hline 3 & Yes/No & $X, 1,15,16,17,18,21,22$ & $-8,-13, \operatorname{der} 13$ & - & $3: 1$ & 3PN \\
\hline 4 & Yes/No & $X, 1,15,16,17,18,21,22$ & $+\operatorname{der} 13$ & - & $3: 1$ & Fertilized \\
\hline 5 & Lost/No & - & - & - & & Fertilized \\
\hline 6 & Yes/No & - & -8, der $8,13^{\text {rec }}$ & $\begin{array}{l}X, 1,15,16,17,18 \\
21,22\end{array}$ & $\begin{array}{l}2: 2 \text { alternate or } \\
\text { adjacent } 1\end{array}$ & Fertilized \\
\hline 7 & Yes/No & $X, 15,16,17,18,21,22$ & $8,13^{\text {rec }},+1$ & - & $\begin{array}{l}\text { 2:2 alternate or } \\
\text { adjacent } 1\end{array}$ & $3 \mathrm{PN}$ \\
\hline 8 & Yes/No & $X, 1,15,17$ & -8, der8 & $13,16,18,21,22$ & $3: 1$ & Fertilized \\
\hline 9 & Yes/No & $\mathrm{X}, 1,8,13,17$ & - & $15,16,18,21,22$ & $2: 2$ alternate $(\mathrm{N})$ & $3 \mathrm{PN}$ \\
\hline 10 & Yes/No & Lost during FISH & - & - & - & Fertilized \\
\hline 11 & Yes/No & $X, 1,15,16,18,22$ & $8,13^{\text {rec }}$ & 17,21 & $\begin{array}{l}2: 2 \text { alternate or } \\
\text { adjacent } 1\end{array}$ & Degenerated \\
\hline $\begin{array}{l}\text { Patient } 2 \\
\text { Cell number }\end{array}$ & $\begin{array}{l}\text { Fixed } \\
\text { 1PB/Blt }\end{array}$ & Euploidy & Aneuploidy & $\begin{array}{l}\text { Undiagnosed } \\
\text { chromosomes }\end{array}$ & $\begin{array}{c}\text { 13,14,der13/14 } \\
\text { segregation }\end{array}$ & $\begin{array}{l}\text { ICSI results } \\
\text { and transfer }\end{array}$ \\
\hline 1 & Yes/No & $X$ & $+\operatorname{der} 13 / 14,-\operatorname{cht} 16,+18,+22$ & $1,15,17,21$ & $3: 0$ & Fertilized \\
\hline 2 & Yes/No & $\begin{array}{l}X, 13,14 \text { or } 13 / 14,15,17 \\
18,22\end{array}$ & +1 & 16,21 & $\begin{array}{l}2: 1 \text { alternate }(\mathrm{N} \\
\quad \text { or } \mathrm{B})\end{array}$ & Degenerated \\
\hline 3 & Yes/No & Lost during FISH & - & - & - & Fertilized \\
\hline 4 & Yes/No & $1,13,14,15,18,21,22$ & $+\operatorname{cht} X,+\operatorname{chrt} 16,-\operatorname{cht} 17$ & - & $2: 1$ alternate $(\mathrm{N})$ & Fertilized \\
\hline 5 & Yes/No & $X, 13,14,15,16,17,18,21,22$ & - cht1 & - & 2:1 alternate $(\mathrm{N})$ & Fertilized \\
\hline 6 & Yes/No & $\begin{array}{l}X, 1,13,14,15,16,17,18 \\
\quad 21,22\end{array}$ & - & - & 2:1 alternate $(\mathrm{N})$ & $\begin{array}{l}\text { Fertilized - } \\
\text { transferred }\end{array}$ \\
\hline 7 & Yes/No & $X, 1,13,14,16,17,18,22$ & $-\operatorname{cht} 15,+$ cht 21 & - & 2:1 alternate $(\mathrm{N})$ & Fertilized \\
\hline 8 & Yes/No & $\mathrm{X}, 15,17$ & $-1,-13,-14,+\operatorname{cht} 18,-21$ & 16,22 & $3: 0$ & $1 \mathrm{PN}$ \\
\hline 9 & Yes/No & $13,16,18,21$ & +22 & $X, 1,14,15,17$ & $\begin{array}{l}\text { 2:1 alternate or } \\
\text { adjacent }\end{array}$ & Fertilized \\
\hline 10 & Yes/No & $13,14,15,17,21$ & $-X,-1,-16,-18$ & 22 & 2:1 alternate $(\mathrm{N})$ & Fertilized \\
\hline 11 & Yes/No & $X, 1,13,15,16,17,18,21$ & +22 & 14 & $\begin{array}{l}\text { 2:1 alternate or } \\
\text { adjacent }\end{array}$ & Fertilized \\
\hline 12 & Yes/No & $1,13,15,18,21,22$ & $-\operatorname{cht} X,+14,+\operatorname{cht} 16,-17$ & - & $2: 1$ adjacent & Fertilized \\
\hline 13 & Yes/No & $X, 1,13,15,17,21,22$ & $+14,+16,+18$ & - & $2: 1$ adjacent & Fertilized \\
\hline $\begin{array}{l}\text { Patient } 3 \\
\text { Cell number }\end{array}$ & $\begin{array}{c}\text { Fixed } \\
\text { 1PB/Blt }\end{array}$ & Euploidy & Aneuploidy & $\begin{array}{l}\text { Undiagnosed } \\
\text { chromosomes }\end{array}$ & $\begin{array}{c}\text { 13,14,der13/14 } \\
\text { segregation }\end{array}$ & $\begin{array}{l}\text { ICSI results } \\
\text { and transfer }\end{array}$ \\
\hline 1 & Yes/No & $15,16,17,18,21$ & $-\operatorname{cht} X,+13,-14$ & 22 & $2: 1$ adjacent & Fertilized \\
\hline 2 & Yes/No & $13,14,15,16,17,18,21,22$ & $+\operatorname{cht} X$ & - & 2:1 alternate $(B)$ & Unfertilized \\
\hline 3 & Yes/No & $\mathrm{X}, 15,18,22$ & $\begin{array}{l}+ \text { chtder } 13 / 14,- \text { cht } 13 \\
-16,+17,+21\end{array}$ & - & $3: 0$ & Fertilized \\
\hline 4 & Yes/No & $13,16,18,21,22$ & $+\operatorname{cht} 14$ & $X, 15,17$ & 2:1 adjacent - cht 14 & Fertilized \\
\hline 5 & Yes/No & $X, 13,14,15,16,17,18,21$ & + cht 22 & - & $\begin{array}{l}2: 1 \text { alternate }(\mathrm{N} \\
\text { or } \mathrm{B})\end{array}$ & Unfertilized \\
\hline 6 & Yes/No & $13,16,18$ & + cht $14,+21,+$ cht 22 & $X, 15,17$ & 2:1 adjacent - cht 14 & Fertilized \\
\hline 7 & Yes/Yes & $13,14,18,21,22$ & $+\operatorname{cht} 16^{\mathrm{a}}$ & $\mathrm{X}^{\mathrm{a}}, 15^{\mathrm{a}}, 17^{\mathrm{a}}$ & $\begin{array}{l}2: 1 \text { alternate }(\mathrm{N} \\
\text { or } \mathrm{B})\end{array}$ & $\begin{array}{l}\text { Fertilized - } \\
\text { transferred }\end{array}$ \\
\hline 8 & Yes/Yes & $X, 18,22$ & $-\operatorname{cht} 15,-\operatorname{cht} 17$ & $13^{\mathrm{a}}, 14,16,21$ & $2: 1$ adjacent or $3: 0$ & Fertilized \\
\hline 9 & Yes/Yes & $15,16,17,18,21,22$ & $-\operatorname{cht} X^{a},+\operatorname{der} 13 / 14^{b},-14^{b}$ & - & 2:1 adjacent & Unfertilized \\
\hline 10 & Yes/No & $X, 13,14,15,16,17,18,21,22$ & - & - & $2: 1$ alternate $(B)$ & Fertilized \\
\hline 11 & Yes/Yes & $X, 15,16,17,18,21,22$ & - & $13^{\mathrm{c}}, 14^{\mathrm{a}}$ & 2:1 adjacent & Fertilized \\
\hline 12 & Lost/Yes & - & - & $\begin{array}{l}X^{\mathrm{d}}, 13^{\mathrm{d}}, 14^{\mathrm{c}}, 15^{\mathrm{c}}, 16^{\mathrm{d}}, \\
\quad 17^{\mathrm{d}}, 18^{\mathrm{d}}, 21^{\mathrm{d}}, 22^{\mathrm{d}}\end{array}$ & Parthenogenetic & Unfertilized \\
\hline
\end{tabular}

blt: blastomere; cht: chromatid; -: hypohaploid; +: hyperhaploid; $13^{\text {rec }}$ : chromosome 13 with a normal and a recombinant chromatid; N: normal; B: balanced.

${ }^{a}$ Diagnosed as normal in blastomere; ${ }^{b}$ confirmed in blastomere; ${ }^{c}$ diagnosed in blastomere as extra chromosome; ${ }^{d}$ normal if the embryo is parthenogenetic (one chromosome of each pair). 
Table 3. Estimation of the risk of aneuploidy for the chromosomes analysed by aneuploidy screening and for the oocytes produced per patient

\begin{tabular}{|c|c|c|c|c|}
\hline & $\begin{array}{c}\text { Patient } 1 \\
45, \mathrm{XX}, \operatorname{der}(8 ; 13)(\mathrm{q} 24.1 ; \mathrm{q} 22)\end{array}$ & $\begin{array}{c}\text { Patient } 2 \\
45, \mathrm{XX}, \operatorname{der}(13 ; 14)(\mathrm{q} 10 ; \mathrm{q} 10)\end{array}$ & $\begin{array}{c}\text { Patient } 3 \\
45, X X, \operatorname{der}(13 ; 14)(q 10 ; q 10)\end{array}$ & Control oocytes \\
\hline $\begin{array}{l}\text { Range of abnormal } \\
\text { segregation per analysed } \\
\text { chromosomes }^{\mathrm{a}}\end{array}$ & $0-1.92 \%$ & $0.9-5.40 \%$ & $0-3.64 \%$ & $0.52-1.70 \%$ \\
\hline $\begin{array}{l}\text { Average of abnormal } \\
\text { segregation per analysed } \\
\text { chromosomes }\end{array}$ & $0.24 \%$ & $3.11 \%$ & $2.20 \%$ & $0.89 \%$ \\
\hline $\begin{array}{l}\text { Estimated risk of } \\
\text { aneuploidy per oocyte } \\
\text { produced }^{b}\end{array}$ & $22 \%$ & $88 \%$ & $66 \%$ & $57.2 \%$ \\
\hline
\end{tabular}

${ }^{a}$ Data calculated for each chromosome, dividing the number of altered chromosomes into the total number of diagnosed chromosomes and multiplied per one hundred.

${ }^{\mathrm{b}}$ The risk of aneuploidy was calculated using the distribution of aneuploidies found in patients and in control oocytes. This distribution fits a Poisson with parameters of $0.25,2.08,1.09$ and 0.85 , respectively (calculated according to Kolmogorov-Smirnov adjustment).

Table 4. Global results of preimplantation genetic diagnosis-first polar body (PGD-1PB) in the ten-chromosome analysis of one reciprocal and two Robertsonian translocation carriers

\begin{tabular}{|c|c|c|c|}
\hline & & Normal oocytes & Abnormal oocytes \\
\hline Patient 1 & Translocation analysis & $1+3^{a}$ & $5+3^{a}$ \\
\hline \multirow[t]{2}{*}{ 45,XX, der(8;13)(q24.1;q22) } & Aneuploidy screening & 3 & 1 \\
\hline & Final results & $1^{b}$ & 8 \\
\hline Patient 2 & Translocation analysis & 6 & 6 \\
\hline \multirow{2}{*}{$45, X X, \operatorname{der}(13 ; 14)(q 10 ; q 10)$} & Aneuploidy screening & 1 & 11 \\
\hline & Final results & 1 & 11 \\
\hline Patient 3 & Translocation analysis & 4 & 7 \\
\hline \multirow[t]{2}{*}{$45, X X, \operatorname{der}(13 ; 14)(q 10 ; q 10)$} & Aneuploidy screening & 3 & 8 \\
\hline & Final results & 1 & 10 \\
\hline
\end{tabular}

aThese three cells have been included as normal and abnormal because they had a recombinant chromosome 13 with a normal and a derivative chromatid, and therefore could produce a normal or an abnormal zygote with a probability of $50 \%$.

${ }^{\mathrm{b}}$ This cell was euploid for the chromosomes diagnosed (1PB number 9, patient 1), but some chromosomes were undiagnosed.

The distribution of aneuploidies found in patients 1 , 2 and 3 and in control oocytes (Pujol et al., 2003) fits a Poisson with parameters of 0.25, 2.08, 1.09 and 0.85 , respectively (calculated according to KolmogorovSmirnov adjustment). A risk of aneuploidy per oocyte produced per patient could be estimated using these distributions; the values were $22 \%$ for patient $1,88 \%$ for patient $2,66 \%$ for patient 3 , and $57.2 \%$ for control oocytes.

\section{Global results in 1 PBs}

For patient 1 , one of nine 1 PBs $(11.1 \%)$ was euploid for the chromosomes implicated in the reorganization, although another three $1 \mathrm{PBs}$ showed a recombinant chromosome 13 that could produce balanced embryos with a frequency of $50 \%$. Three of four diagnosed cells $(75 \%)$ were euploid for all other chromosomes analysed
(Table 4). Unfortunately, the only oocyte which was balanced for the reorganization and euploid for the other diagnosed chromosomes produced a 3 pronucleus (PN) zygote and was not transferred (Table 2, cell 9). Six of $12(50 \%)$ 1PBs for patient 2 were euploid for the chromosomes implicated in the reorganization but five of them were abnormal after aneuploidy screening (Table 4). Only one of 12 analysed 1PBs was eventually euploid for all the chromosomes analysed (Table 2, cell 6); the resulting embryo was of the highest quality, corresponding to a score of ten according to Plachot et al. (1990), and was transferred under ultrasound scanning control but no pregnancy was achieved.

Four of $11(36.4 \%) 1 \mathrm{PBs}$ for patient 3 were euploid for the chromosomes implicated in the reorganization but three were abnormal after aneuploidy screening (Tables 2 and 4). Only one of 11 analysed 1PBs was euploid for all the chromosomes analysed (Table 2, cell 10) but 


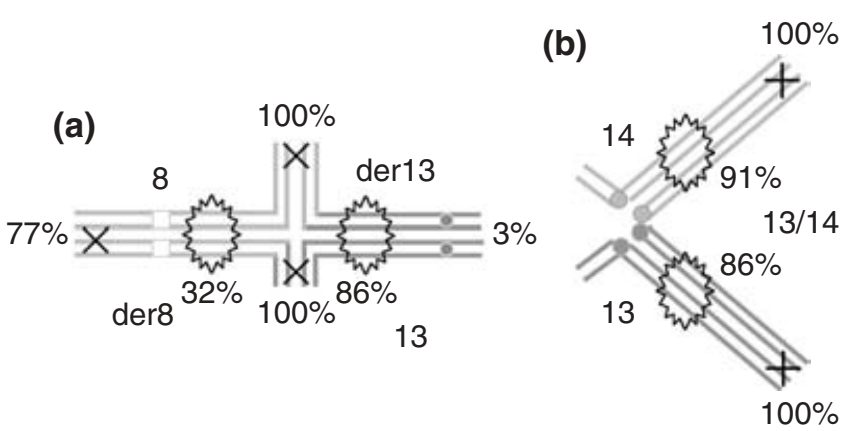

Fig. 3. Meiotic recombination frequency in (a) the quadrivalent resulting from the $(8 ; 13)$ reciprocal translocation, and (b) the trivalent resulting from the $(13 ; 14)$ Robertsonian translocation. (Redrawn from Laurie and Hultén, 1985a,b).

the resulting embryo was morphologically abnormal and could not be transferred. Oocyte number 7 had only one chromatid alteration but the blastomere was euploid and the embryo was transferred under ultrasound scanning control; unfortunately, no pregnancy was achieved.

It is important to point out that most of the aneuploid oocytes found in patients 2 and 3 had, at least, an hyperhaploidy for one chromosome. Nine of 11 aneuploid oocytes $(81.8 \%)$ for patient 2 and nine out of ten (90\%) aneuploid oocytes for patient 3 had from one to three extra chromosomes and, one or two of them were not involved in the translocation.

\section{Embryo analysis}

Embryos from patients 1 and 2 were not suitable for biopsy on day 3 . One blastomere from embryos 7,8 , 9, 11 and 12 from patient 3 could be biopsied on day 3 after follicular puncture to complete the diagnosis carried out in 1PBs. Results of 1PB and blastomere analysis are detailed in Table 2. Briefly, in embryo 7, the blastomere was euploid so that the chromatid alteration detected in $1 \mathrm{~PB}$ for chromatid 16 had been eliminated in the second meiotic division. A diagnosis for chromosome 13 was achieved in embryo 8 . The chromatid $\mathrm{X}$ alteration observed in $1 \mathrm{~PB}$ was eliminated in the second meiotic division and the abnormalities for chromosomes 13 and 14 were confirmed in embryo 9. A diagnosis for chromosomes 13 and 14 was achieved in embryo 11 . A parthenogenetic cell division of an aneuploid oocyte was detected in embryo 12.

The discarded embryos were only available to be analysed by FISH for patient 1; seven embryos were analysed for the translocation. Five of the seven embryos were mosaics: in two of them the diagnosis established by analysing $1 \mathrm{~PB}$ was confirmed in $75 \%$ and $66.7 \%$ of the analysed nuclei; in three embryos each nucleus showed a different content. The other two embryos had two or more nucleus fragments with a number of signals that were difficult to interpret.

\section{Discussion}

In a reciprocal translocation, the only segregation pattern that gives normal or balanced embryos is the 2:2 alternate, in which the two normal chromosomes segregate to one pole, whereas the two derivatives go to the other. In a Robertsonian translocation, the only segregation pattern that gives normal or balanced embryos is the 2:1 alternate, in which the two normal chromosomes segregate to one pole, whereas the derivative chromosome goes to the other.

The frequency of normal or balanced segregation was quite low, $11.1 \%$ ( 1 of 9 ) for patient 1 in the present study. When chromosome 13 is implicated in reciprocal translocations, and there is a high frequency of recombination $(86 \%$ according to Laurie and Hultén $(1985 a, b))$, in the interstitial region of the tetravalent formed by chromosomes 8 and 13 in meiosis I (the present study) (Fig. 3a), chromosomes with unequal chromatids are produced as in 1PB numbers 6, 7 and 11. In this case, it is impossible to distinguish between alternate and adjacent 1 segregation and the exchange may favour an adjacent segregation (Durban et al., 2001). For patients 2 and 3 in the present study, the frequency of normal or balanced segregation was $50 \%$ (6 of 12) and $44.4 \%$ (4 of 9), respectively. Obviously, when chromosome 13 is involved in Robertsonian translocations, unequal chromatids are never found because there is no interstitial region in the trivalent formed in meiosis I (Fig. 3b).

An increase in chromatid pre-division (Angell et al., 1991) with maternal age has been described by Sandalinas et al. (2002). Differences in maternal age could explain why, in the present study, chromatid predivision was never observed in patient 1 , whereas in patients 2 and 3 it was extremely frequent. Patients 2 and 3 were over 35 years of age and belonged to the same age group as that in which Sandalinas et al. (2002) found an increase in chromatid pre-division.

However, the fact that for patient 1 , one single aneuploidy was detected, whereas for patients 2 and 3 multiple, random aneuploidies were seen in 11 of 12 $(91.7 \%)$ and 8 of $11(72.7 \%)$ oocytes, respectively, also indicates that patients 2 and 3 could have a generalized tendency to non-disjunction, as demonstrated in some women in IVF programmes (Zenzes et al., 1992) or in the fathers of children with trisomy 21 of paternal origin (Reis-Soares et al., 2001).

Abnormal segregation frequencies were calculated according to a control analysis made with in vitromatured oocytes from IVF patients (Pujol et al., 2003). The present authors used the results of that analysis as a control in the clinical cases because fixed lymphocytes or blastomeres have different hybridization conditions and were considered inappropriate. Two rounds of FISH were performed to detect nine chromosomes (1, 13, 15, 16, 17, 18, 21, 22 and X) in 89 1PBs. The same nine chromosomes were also analysed in 54 
$1 \mathrm{PBs}$ in the corresponding oocyte in MII to confirm the results; the other $351 \mathrm{PBs}$ were analysed alone as when PGD using 1 PB is performed. The frequency of aneuploid oocytes found for the analysed chromosomes was $47.5 \%$; if the risk of aneuploidy for 23 chromosomes was estimated, the percentage increased to $57.2 \%$. As $74.2 \%$ of chromosomes or chromatids missing in the $1 \mathrm{~PB}$ were observed in the corresponding oocyte in MII, every hypohaploidy contributing 0.74 instead of one when counting the total number of aneuploidies was considered. The range of abnormal segregation per chromosome was $0.52-1.70 \%$ and the average was $0.89 \%$.

The pairing figures formed at pachytene in reciprocal and Robertsonian translocations are different and have a different level of homologous pairing. Most quadrivalents achieve the complete pairing of all chromosome regions, and often produce stable ring configurations, whereas in trivalents the short arms of the normal chromosomes cannot pair with the missing short arms of the translocated chromosomes, and furthermore the trivalent results in an unstable chain configuration. The low aneuploidy rate found in the reciprocal translocation carrier indicates that the quadrivalent formed in the case analysed did not induce the abnormal segregation of chromosomes not involved in the rearrangement. Patient 1 had a lower risk of producing aneuploid oocytes than controls, although the high aneuploidy rate found in control oocytes could be due to the fact that they were matured in vitro (Volarcik et al., 1998).

However, Robertsonian translocation carriers had a higher risk (significant for patient 2) of producing aneuploid oocytes, also observed by Gianaroli et al. (2002). These authors also reported, in normal karyotype age-matched patients from ICSI cycles, $17 \%$ of embryos with monosomies or trisomies; this frequency was similar to the aneuploidy rate found in reciprocal translocation carriers and was significantly lower when compared with Robertsonian translocations. The reason for the mentioned aneuploidy higher risk of Robertsonian translocation carriers may be that the incomplete pairing of the chromosomes of the trivalent can generate some instability in other bivalents (Navarro et al., 1991). This results in pairing anomalies that can affect the alignment of chromosomes in the spindle (Eichenlaub-Ritter et al., 1999); in the female this situation can result in multiple aneuploidies.

The high frequency of abnormal oocytes produced by translocation carriers is striking, but it has been observed not only in oocytes but also in embryos (Conn et al., 1998; Van Assche et al., 1999; Durban et al., 2001).

Although several rounds of FISH on the same cell have also been applied with high success rates (Escudero et al., 1998; Bahçe et al., 2000), in the present study in some cells, the consecutive DNA denaturation resulted in confusing FISH signals that did not allow diagnosis of some chromosomes, thus increasing the number of chromo- somes that could not be diagnosed but not the number of FISH errors. As a result of the use of multiple rounds of $\mathrm{FISH}$, hybridization failures occurred with different frequencies in the present study. In practice, when one or more chromosome anomalies have been detected, hybridization failures make no difference because the cell is considered aneuploid and is discarded. On the other hand, in cells that are euploid for the chromosomes diagnosed but in which some chromosomes are undiagnosed, the problem becomes evident. However, if an oocyte is undiagnosed or shows only chromatid alterations that can be rescued in the second meiotic division, as ICSI is carried out before 1PB biopsy and not later than $2 \mathrm{~h}$ after follicular puncture, the embryo has reached the 6-8-cell stage after completion of the $1 \mathrm{~PB}$ analysis, and a blastomere biopsy can be performed and analysed by FISH. Evidence of this compensatory mechanism generating euploid zygotes has been reported (Verlinsky and Kuliev, 2000).

A high frequency of $3 \mathrm{PN}$ zygotes was observed in patient 1 in the present study. The only oocyte that was balanced for the reorganization and euploid for the other diagnosed chromosomes produced a 3PN zygote and was not transferred. This high frequency of abnormal zygotes was probably due to the non-extrusion of the second polar body (Grossman et al., 1997).

Embryo development was, in general, quite slow. Patient 1 had only two embryos with four or more cells on day 2. Patient 2 had slower development with only five embryos having six or more cells on day 3. Patient 3 had only two embryos with six or more cells on day 3 . It could be argued that this was due to the aneuploidy. If aneuploidy could be a cause or a consequence of the slow embryo development, it should be analysed in more clinical cases.

Although the incidence of aneuploidies in humans is quite high, relatively little is known about how they are generated. An extensive review of current molecular and cytogenetic approaches has been published in which factors that could generate human aneuploidies are analysed (Hassold and Hunt, 2001).

The origin of the aneuploidies affecting chromosomes not implicated in the translocation may be related to several factors. An increase in oocyte aneuploidy with advanced maternal age has been found in many studies (Plachot et al., 1988; Navot et al., 1991; Angell et al., 1993; Dailey et al., 1996; Bahçe et al., 1999). In the present work, patient 1 (34 years old) showed the lowest aneuploidy rate $(11.1 \%)$. Patients 2 and 3 were 39 and 36 years old, respectively, and both showed a high aneuploidy rate $(91.7 \%$ and $81.8 \%)$. Advanced maternal age explains, in part, the high aneuploidy rate in patient 2, but in patient 3 advanced maternal age should not be the main cause. The fact that Robertsonian translocation carriers had a higher aneuploidy rate for the chromosomes not involved in the rearrangement than the reciprocal translocation carrier may be caused by 
synaptic defects in the trivalent formed during meiosis $\mathrm{I}$ in Robertsonian translocations, and may result in heterosynapses or even the production of univalents; this may delay chromosome congression and interfere with the spindle checkpoint, producing chromosome aneuploidies (Eichenlaub-Ritter et al., 1999). Synaptic defects may also allow maturation of MII kinetochores and result in pre-division (Flatters et al., 1995).

It is worth noting that a high extent of mosaicism affecting chromosomes not implicated in a rearrangement in human embryos has also been detected in patients with balanced structural chromosome aberrations (Iwarsson et al., 2000; Malmgren et al., 2002; Emiliani et al., 2003).

It is important to know the chromosome constitution of the oocyte not only for the chromosomes implicated in the reorganization but also for those more frequently implicated in aneuploidies (Bahçe et al., 1999). Although the number of theoretically transferable embryos would undoubtedly be much higher if only the chromosomes involved in the translocation were analysed, the pregnancy rate would probably not change and more abortions would probably be produced because aneuploidies could be present in some of the apparently normal or balanced oocytes. The presence of undetected aneuploidies could explain the miscarriage of patients 2 and 3 in their first PGD-1PB cycle, in which three apparently normal or balanced embryos were transferred but first trimester miscarriages were produced.

The best solution would be to karyotype the $1 \mathrm{PBs}$ using the appropriate combination of probes, or Multiple-FISH (M-FISH). However, as this is difficult and expensive, an alternative could be to perform a complete cytogenetic analysis of the $1 \mathrm{PBs}$ using compared genomic hybridization (CGH) (Wilton et al., 2001; Wells et al., 2002), DNA arrays in single cells or FISH with centromeric probes for the 23 chromosomes (cenM-FISH; Nietzel et al., 2001) to choose chromosomally normal embryos for transfer.

A high aneuploidy rate for chromosomes not implicated in translocations has already been found using blastomere analysis (Gianaroli et al., 2002), but the paternal or maternal origin could not be identified, even though they most probably originated in the oocyte. The present work is the first showing a definite maternal origin of aneuploidies, mostly hyperhaploidies, not explained only by maternal age. More cases of PGD-AS on translocation carriers would be necessary to know if the tendency to aneuploidies is case-specific or is a consequence of a meiotic behaviour associated with reciprocal or Robertsonian translocations.

This work has been supported by Ministerio de Sanidad (FIS PI-020168), DURSI (2001 SGR-00104) and Fundació Catalana Síndrome de Down/Marató de TV3 (1994-1998). It has also been supported by Departament d'Universitats, Recerca i Societat de la Informació de la Generalitat de Catalunya (A. Pujol has a Beca Predoctoral de Formació de Personal Investigador; FI/FIAP).

\section{References}

Angell RR, Ledger W, Yong E, Harkness L and Baird DT (1991) Cytogenetic analysis of unfertilized human oocytes Human Reproduction 6 568-573

Angell RR, Xian J and Keith J (1993) Chromosome anomalies in human oocytes in relation to age Human Reproduction 8 1047-1054

Bahçe M, Cohen J and Munné S (1999) Preimplantation genetic diagnosis of aneuploidy: were we looking at the wrong chromosomes? Journal of Assisted Reproduction and Genetics 16 176-181

Bahçe M, Escudero T, Sandalinas M, Morrison L, Legator M and Munné S (2000) Improvements of preimplantation diagnosis of aneuploidy by using microwave hybridization, cell recycling and monocolour labelling of probes Molecular Human Reproduction 6 849-854

Conn C, Harper J, Winston R and Delhanty J (1998) Infertile couples with Robertsonian translocations: preimplantation genetic analysis of embryos reveals chaotic cleavage divisions Human Genetics 102 117-123

Conn CM, Cozzi J, Harper JC, Winston RM and Delhanty JD (1999) Preimplantation genetic diagnosis for couples at high risk of Down syndrome pregnancy owing to parental translocation or mosaicism Journal of Medical Genetics 36 45-50

Coonen E, Martini E, Dumoulin JC, Hollanders-Crombach HT, DieSmulders C, Geraedts JP, Hopman AH and Evers JL (2000) Preimplantation genetic diagnosis of a reciprocal translocation $\mathrm{t}(3 ; 11)(\mathrm{q} 27.3 ; \mathrm{q} 24.3)$ in siblings Molecular Human Reproduction 6 199-206

Dailey T, Dale B, Cohen J and Munné S (1996) Association between nondisjunction and maternal age in meiosis-II American Journal of Human Genetics 59 176-184

Durban M, Benet J, Sarquella J, Egozcue J and Navarro J (1998) Chromosome studies in first polar bodies from hamster and human oocytes Human Reproduction 13 583-587

Durban M, Benet J, Boada M, Fernández E, Calafell JM, Lailla JM, SánchezGarcía JF, Pujol A, Egozcue J and Navarro J (2001) PGD in female carriers of balanced Robertsonian and reciprocal translocations by first polar body analysis Human Reproduction Update 7 591-602

Egozcue J (1996) Preimplantation diagnosis in older patients. To biopsy or not to biopsy. Of course, not Human Reproduction 11 2077-2078

Eichenlaub-Ritter U, Cucurkam S, Betzendahl I and Yin H (1999) Studies on the aneugenic properties of trichlorfon, a pesticide, vermicide and drug used in the treatment of Alzheimer patients Human Reproduction 14 240-241

Emiliani S, González-Merino E, Van den Bergh M, Abramowicz M and Englert $\mathbf{Y}$ (2003) Higher degree of chromosome mosaicism in preimplantation embryos from carriers of Robertsonian translocation $\mathrm{t}(13 ; 14)$ in comparison with embryos from karyotypically normal IVF patients Journal of Assisted Reproduction and Genetics 20 95-100

Escudero T, Fuster C, Coll M and Egozcue J (1998) Cytogenetic analysis using simultaneous and sequential fluorescence in situ hybridization Cancer Genetics and Cytogenetics 100 111-113

ESHRE PGD Consortium Steering Committee PGD (2002) Data collection III Human Reproduction 17 233-246

Flatters M, Maxfield R and Dawson D (1995) The effects of a ring chromosome on the meiotic segregation of other chromosomes in Saccharomyces cerevisiae. Molecular and General Genetics 249309 316

Gianaroli L, Magli M, Ferraretti A, Munné S, Balicchia B, Escudero T and Crippa A (2002) Possible interchromosomal effect in embryos generated by gametes from translocation carriers Human Reproduction 173201 3207

Grossman M, Calafell JM, Brandy N, Vanrell J, Rubio C, Pellicer A, Egozcue J, Vidal F and Santaló J (1997) Origin of tripronuclear zygotes after intracytoplasmic sperm injection Human Reproduction 12 2762-2765

Handyside A, Kontogianni E, Hardy K and Winston R (1990) Pregnancies from biopsied human preimplantation embryos sexed by Y-specific DNA amplification Nature 344 768-770

Harper JC, Wells D, Piyamongkol W et al. (2002) Preimplantation genetic diagnosis for single gene disorders: experience with five single gene disorders Prenatal Diagnosis 22 525-533

Hassold T and Hunt $\mathbf{P}$ (2001) To err (meiotically) is human: the genesis of human aneuploidy Nature 2 280-290 
Iwarsson E, Malmgren H, Inzunza J, Ährlund-Richter L, Sjöblom P, Rosenlund B, Fridström $M$, Hovatta $O$, Nordenskjöld $M$ and Blennow $E$ (2000) Highly abnormal cleavage divisions in preimplantation embryos from translocation carriers Prenatal Diagnosis 20 1038-1047

Laurie D and Hultén $\mathbf{M}$ (1985a) Further studies on bivalent chiasma frequency in human males with normal karyotypes Annals of Human Genetics 49 189-201

Laurie D and Hultén M (1985b) Further studies on chiasma distribution and interference in the human male Annals of Human Genetics 49 203-214

Magli C, Sandalinas M, Escudero T, Morrison L, Ferraretti A, Gianaroli L and Munné S (2001) Double locus analysis of chromosome 21 for preimplantation genetic diagnosis of aneuploidy Prenatal Diagnosis 21 1080-1085

Malmgren H, Sahlén S, Inzunza J, Aho $M$, Rosenlund B, Fridström $M$, Hovatta O, Ährlund-Richter L, Nordenskjöld M and Blennow E (2002) Single cell $\mathrm{CGH}$ analysis reveals a high degree of mosaicism in human embryos from patients with balanced structural chromosome aberrations Molecular Human Repoduction 8 502-510

Munné S, Fung J, Cassel M, Márquez C and Weier H (1998a) Preimplantation genetic analysis of translocations: case-specific probes for interphase cell analysis Human Genetics 102 663-674

Munné S, Magli C, Bahçe M, Fung J, Legator M, Morrison L, Cohen J and Gianaroli L (1998b) Preimplantation diagnosis of the aneuploidies most commonly found in spontaneous abortions and live births: $\mathrm{XY}, 13,14,15,16,18,21,22$ Prenatal Diagnosis 18 1459-1466

Munné S, Escudero T, Sandalinas M, Sable D and Cohen J (2000a) Gamete segregation in female carriers of Robertsonian translocations Cytogenetics and Cell Genetics 90 303-308

Munné S, Sapulveda S, Balmaceda J, Fernández E, Fabres C, Mackenna A, López T, Crosby J and Zegers-Hochschild F (2000b) Selection of the most common chromosome abnormalities in oocytes prior to ICSI Prenatal Diagnosis 20 582-586

Navarro J, Vidal F, Benet J, Templado C, Marina S and Egozcue J (1991) $\mathrm{XY}$-trivalent association and synaptic anomalies in a male carrier of a Robertsonian $\mathrm{t}(13 ; 14)$ translocation Human Reproduction 6 376381

Navot D, Bergh P, Williams M, Garrisi G, Guzman I, Sandler B and Grunfeld L (1991) Poor oocyte quality rather then implantation failure as a cause of age-related decline in female fertility The Lancet 337 1375-1377

Nietzel A, Rocchi M, Starke H, Heller A, Fiedler W, Wlodarska I, Loncarevic I, Beensen V, Claussen U and Liehr T (2001) A new multicolor-FISH approach for the characterization of marker chromosomes: centromerespecific multicolor-FISH (cenM-FISH) Human Genetics 108 199204

Plachot M, Veiga A, Montagut J et al. (1988) Are clinical and biological parameters correlated with chromosomal disorders in early life: a multicentric study Human Reproduction 3 627-635

Plachot M, Mandelbaum J and Junca A (1990) Qualite de l'oocyte et de l'embryon et resultat de la FIV Contraception, Fertility and Sexuality 18 636-638
Pujol A, Boiso I, Benet J, Veiga A, Durban M, Campillo M, Egozcue J and Navarro J (2003) Analysis of nine chromosome probes in 1st Polar Bodies and metaphase II oocytes for the detection of aneuploidies European Journal of Human Genetics 11 325-336

Reis-Soares S, Templado C, Blanco J, Egozcue J and Vidal F (2001) Numerical chromosome abnormalities in the spermatozoa of the fathers of children with trisomy 21 of paternal origin: generalised tendency to meiotic non-disjunction Human Genetics 108 134-139

Sandalinas M, Márquez C and Munné S (2002) Spectral karyotyping of fresh, non-inseminated oocytes Molecular Human Reproduction 8580 585

Van Assche E, Staessen C, Vegetti W, Bonduelle M, Vandervorst $M$, Van Steirteghem A and Liebaers I (1999) Preimplantation genetic diagnosis and sperm analysis by fluorescence in situ hybridization for the most common reciprocal translocation $\mathrm{t}(11 ; 22)$ Molecular Human Repoduction 5 682-690

Verlinsky Y, Cieslak J, Freidine M et al. (1996) Polar body diagnosis of common aneuploidies by FISH Journal of Assisted Reproduction and Genetics 13 157-162

Verlinsky Y (1999) Preimplantation diagnosis: an alternative to prenatal diagnosis of genetic and chromosomal disorders Journal of Assisted Reproduction and Genetics 16 161-164

Verlinsky Y, Cieslak J, Ivakhnenko V et al. (1999) Prevention of agerelated aneuploidies by polar body testing of oocytes Journal of Assisted Reproduction and Genetics 16 165-169

Verlinsky Y and Kuliev A (2000) Fluorescence in situ hybridization analysis of polar bodies and blastomeres. In Preimplantation Genetic DiagnosisAtlases I pp 31-37. Parthenon Publishing Group, New York

Volarcik K, Sheean L, Goldfarb J, Woods L, Abdul-Karim F and Hunt P (1998) The meiotic competence of in vitro matured human oocytes is influenced by donor age: evidence that folliculogenesis is compromised in the reproductively aged ovary Human Reproduction 13 154-160

Wells D, Escudero T, Levy B, Hirschhorn K, Delhanty J and Munné S (2002) First clinical application of comparative genomic hybridization and polar body testing for preimplantation genetic diagnosis of aneuploidy Fertility and Sterility 78 543-549

Wilton L, Williamson R, McBain J, Edgar D and Voullaire L (2001) Birth of a healhy infant after preimplantation confirmation of euploidy by comparative genomic hybridisation New England Journal of Medicine 345 1537-1541

Zenzes M, Wang P and Casper R (1992) Evidence for maternal predisposition to chromosome aneuploidy in multiple oocytes of some in vitro fertilisation patients Fertility and Sterility 57 143-149

Received 27 June 2003.

First decision 28 August 2003

Revised manuscript received 4 September 2003.

Accepted 12 September 2003. 